\title{
A PROOF-OF-CONCEPT STUDY: DETERMINING THE GEOGRAPHICAL ORIGIN OF CRUDE PALM OIL WITH THE COMBINED USE OF GC-IMS FINGERPRINTING AND CHEMOMETRICS
}

GOGGIN, K A*; BRODRICK, E**; WICAKSONO, A*; COVINGTON, J A ; DAVIES, A N‡ and MURPHY, D J*

\begin{abstract}
Current administrative controls used to verify geographical provenance within palm oil supply chains require enhancement and strengthening by more robust analytical methods. In this study, the application of volatile organic compound fingerprinting, in combination with five different analytical classification models, has been used to verify the regional geographical provenance of crude palm oil (CPO) samples. For this purpose, 108 CPO samples were collected from two regions within Malaysia, namely Peninsular Malaysia (32) and Sabah (76). Samples were analysed by gas chromatography-ion mobility spectrometer (GC-IMS) and the five predictive models (Sparse Logistic Regression, Random Forests, Gaussian Processes, Support Vector Machines and Artificial Neural Networks) were built and applied. Models were validated using 10-fold cross-validation. The area under curve (AUC) measure was used as a summary indicator of the performance of each classifier. All models performed well (AUC 0.96) with the Sparse Logistic Regression model giving best performance ( $A U C=0.98$ ). This demonstrates that the verification of the geographical origin of CPO is feasible by volatile organic compound fingerprinting, using GC-IMS supported by chemometric analysis.
\end{abstract}

Keywords: chemometrics, fingerprinting, GC-IMS, geographical origin, palm oil, volatile organic compounds.

Received: 8 January 2020; Accepted: 16 April 2020; Published online: 7 April 2021.

\section{INTRODUCTION}

Palm oil obtained from the fruit of the oil palm (Elaeis guineensis), is the most consumed vegetable oil globally. In 2018, it was estimated that 68 million tonnes were produced globally (Statista, 2018). The oil palm plant originates from West Africa,

\footnotetext{
* Faculty of Computing, Engineering and Science, University of South Wales, Pontypridd, CF37 1DL, United Kingdom.

E-mail: denis.murphy@southwales.ac.uk

** IMSPEX Diagnostics Ltd, Ty Menter Navigation Park, Abercynon CF45 4SN, United Kingdom.

₹ School of Engineering, University of Warwick, Library Rd, Coventry CV4 7AL, United Kingdom.

抹 Nouryon, 7418 AJ Zutphenseweg 10, P.O. Box 10, 7400 AA, Deventer, The Netherlands.
}

but now grows in wild, semi-wild and cultivated states right across the equatorial tropics, including Malaysia, Indonesia, Papua New Guinea, Western Africa and South and Central America (Corley and Tinker, 2008). Two different oils are extracted from palm fruits, namely crude palm oil (CPO) and crude palm kernel oil. CPO is the main oil of commercial interest, being semi-solid at room temperature and containing high proportions of both saturated and monounsaturated fatty acids. These properties make for a versatile oil that is predominantly used in foodstuffs as an ingredient in thousands of processed foods ranging from noodles to chocolate. Oil palm cultivation has grown rapidly in recent decades due to low production costs and high demands from the food industry, especially for CPO (Corley and Tinker, 2008; Paddison et al., 2014). 
The initial rapid expansion of the oil palm industry in Malaysia occurred by conversion of land from other plantation crops, mainly rubber. However, after 2000, large tracts of primary and secondary rainforests, as well as peatlands, were also converted especially in Indonesia. This process often occurred in regions of high biodiversity and conservation value (Koh and Wilcove, 2008; Meijaard et al., 2018). As a reaction to this process, the Roundtable on Sustainable Palm Oil (RSPO) was established in 2004 to improve sustainability and traceability of the industry. However, to a great extent, current traceability methods are largely based upon potentially fallible audit trails. Therefore, it is increasingly important that there are alternative methodologies that can be applied reliably within supply chains and which enable authentication of geographical provenance, to facilitate current traceability measures.

Chemically-based methods for the authentication of geographical provenance of vegetable oils has been well studied in the case of olive oil but less so for other oils (Janin et al., 2014; Ou et al., 2015; Portarena et al., 2014). All vegetable oils are complex natural mixtures comprising of many components. Fatty acid composition is the most studied component for vegetable oil authentication (Janin et al., 2014; Korifi et al., 2011; Tres et al., 2013). However, other important components can also be utilised for authentication including sterols, elemental isotope ratios, volatile organic compounds (VOC) and tocopherols. With the exception of isotope ratios, fingerprinting techniques are the most common approach for assessing such components, as they provide analytical information about a sample in a nonselective way (Ruiz-Samblás et al., 2013).

However, fingerprinting usually generates issues of 'big data' analysis, which require the use of appropriate multivariate statistics to extract the most important information for characterising a particular sample (Cumeras et al., 2015; Hauschild et al., 2012; Szymanska et al., 2014). Other studies have shown that VOC fingerprints can be useful for discerning vegetable oils by geographical origin because their quality and composition depend on several factors, including genetic variety, growing conditions, processing technologies and storage (Tres et al., 2011). In the case of palm oils, the composition may be significantly affected by seasonal variation, fertilisation regime, oil processing techniques, etc.

In this work, gas chromatography-ion mobility spectrometer (GC-IMS) was used to generate VOC fingerprints. IMS was initially developed in the 1970s for detection of explosives and chemical warfare agents. It relies upon the separation of charged particles in an electric field, with separation depending upon mass, shape, size and collisional cross-sectional area (Eiceman et al., 2016) of each ion cluster. However, ion mobility spectrometers typically have low resolution due to overlapping signals resulting from ion-ion or ion-molecule reactions in the ionisation process (Garrido-Delgado et al., 2011). In this work, we explored the use of an IMS. The method is therefore often coupled with other techniques for fast preseparation, usually a standard GC column, as is the case in this study. GC-IMS is now increasingly applied in the environmental, biomedical and food and flavour industries due to its selectivity and sensitivity, time of analysis, small footprint, low cost and its ability for easy on-site implementation by relatively unskilled operatives, meaning it is potentially accessible to laboratories worldwide.

The present work is one of only a few studies that have sought to characterise $\mathrm{CPO}$ samples by geographical origin. Four previous studies have sought to do this on a continental scale (South-east Asia vs. South America vs. Africa) (Obisesan et al., 2017; Pérez-Castaño et al., 2015; Ruiz-Samblás et al., 2013; Tres et al., 2013) and one study was on a regional scale (central Malaysia vs. northern Malaysia vs. east coast Malaysia vs. southern Malaysia vs. east Malaysia) (Muhammad et al., 2017). While, GC-IMS has previously been used to distinguish different olive oil samples by grade (Garrido-Delgado et al., 2015; 2011), to our knowledge this study is the first time GC-IMS has been used for palm oil analysis. Here we describe the application of chemometrics to raw GC-IMS chromatograms to successfully establish models for the prediction of regional geographical provenance of CPO samples in Malaysia.

\section{MATERIALS AND METHODS}

\section{Palm Oil Samples}

A total of 108 palm oil samples were provided by the Wageningen University of Research (WUR), The Netherlands. These samples had been collected from various mills across Peninsular Malaysia and the state of Sabah in North Borneo. A total of 32 samples originated from Peninsular Malaysia whilst 76 originated from Sabah. Samples were stored at $4^{\circ} \mathrm{C}$ until analysis.

\section{Sample Preparation}

No pre-preparation or derivatisation of samples is required prior to GC-IMS analysis. CPO samples were melted at $45^{\circ} \mathrm{C}$ to enable aliquoting of $1 \mathrm{~g}$ to a $20 \mathrm{ml}$ glass headspace vial and vials were secured with a magnetic screw cap, sealed with a PTFE/ silicon septum. Samples were pre-conditioned at $60^{\circ} \mathrm{C}$ and $275 \mathrm{rpm}$ for $15 \mathrm{~min}$, via an integrated 
sample introduction system (SIS) unit (CTCPAL, CTC Analytics AG, Zwingen, Switzerland) to ensure equilibration between the sample and headspace. The $200 \mu \mathrm{l}$ of sample headspace was directly injected into the GC-IMS system via a 2.5 $\mathrm{ml}$ Hamilton syringe with a $51 \mathrm{~mm}$ needle.

\section{GC-IMS Analysis}

All CPO analyses were performed on a commercially available GC-IMS instrument (model, FlavourSpec $^{\odot}$ ) from Gesellschaft für Analytische Sensorsysteme mbH (G.A.S., Dortmund, Germany). The headspace sample was injected via a heated splitless injector on to a low polarity GC column consisting of 9\%-diphenyl - 95\% dimethylpolysiloxane of $15 \mathrm{~m}$ length, an internal diameter of $0.53 \mathrm{~mm}$ and $1 \mathrm{~m}$ of film thickness (FSSE-54-CB-1 of CS-Chromatographie Service GmbH, Düren, Germany) facilitated by Nitrogen (6.0) carrier gas. The analytes enter the ionisation region and undergo soft ionisation via a cascade reaction by a Tritium $\mathrm{H}^{3}$ radioactive ionisation source of 300 $\mathrm{MBq}$.

Ion swarms are released into the drift region though a Bradbury Nielsen gate (grid pulse width of $100 \mu \mathrm{s}$ and a sampling frequency of $150 \mathrm{kHz}$ ) when the electric field strength of the grid set of the shutter is weakened or eliminated. Ions travel towards the detector (Faraday plate) against an opposing drift gas (Nitrogen 6.0) and are separated based on mass, charge, size and cross-sectional collision surface area, due to the presence of an electric field. Subsequently, different ions reach the detector at different times, with each component having a specific IMS drift time.

IMS data were acquired in positive mode using Laboratory Analytical Viewer (LAV) software (v.2.0.0) from G.A.S (G.A.S, 2018). Each spectrum had an average of six scans, obtained using a repetition rate of $30 \mathrm{~ms}$. Instrumental and experimental parameters for CPO analysis are displayed in Table 1. Working principles of the FlavourSpec ${ }^{\odot}$ are displayed in Figure 1.

\section{Data Analysis}

GC-IMS spectral data was exported into comma separated values (CSV) format for data processing (typically 11000000 data points per file). The general workflow is summarised in Figure 2 and was developed in $R$ (v 3.0.2). A number

TABLE 1. INSTRUMENTAL AND EXPERIMENTAL PARAMETERS FOR CRUDE PALM OIL (CPO) ANALYSIS

\begin{tabular}{|c|c|}
\hline Parameter & Values and units \\
\hline \multicolumn{2}{|l|}{ Sample Introduction System (SIS) } \\
\hline Sampling type/volume & Headspace $(200 \mu 1)$ \\
\hline Agitation time & $15 \mathrm{~min}$ \\
\hline Incubation temperature & $60^{\circ} \mathrm{C}$ \\
\hline Syringe temperature & $80^{\circ} \mathrm{C}$ \\
\hline \multicolumn{2}{|l|}{ Column } \\
\hline Injector temperature & $80^{\circ} \mathrm{C}$ \\
\hline Capillary column & SE-54 (low polar) ID $0.53 \mathrm{~mm}, 1 \mu \mathrm{m}$ \\
\hline Column length & $15 \mathrm{~m}$ \\
\hline Column temperature & $40^{\circ} \mathrm{C}$ \\
\hline Gas chromatography (GC) run time & $16 \mathrm{~min}$ \\
\hline Carrier gas flow rate & $\begin{array}{l}\mathrm{T}=0-10 \mathrm{~min}: 2 \mathrm{ml} \mathrm{min}^{-1} \text { to } 50 \mathrm{ml} \mathrm{min}^{-1} \\
\mathrm{~T}=10-15 \mathrm{~min}: 50 \mathrm{ml} \mathrm{min}^{-1} \text { to } 150 \mathrm{ml} \mathrm{min}^{-1} \\
\mathrm{~T}=15-16 \mathrm{~min}: 150 \mathrm{ml} \mathrm{min}^{-1} \\
\left(\mathrm{~N}_{2} 6.0\right)\end{array}$ \\
\hline \multicolumn{2}{|l|}{ Ion mobility spectrometer (IMS) } \\
\hline Ionisation source & Tritium (30 MBq) \\
\hline Voltage & Positive drift \\
\hline Drift length & $9.8 \mathrm{~cm}$ \\
\hline Electric field strength & $510 \mathrm{~V} \mathrm{~cm}^{-1}$ \\
\hline Drift gas flow rate & $150 \mathrm{ml} \mathrm{min}-1$ \\
\hline IMS temperature & $45^{\circ} \mathrm{C}$ \\
\hline
\end{tabular}




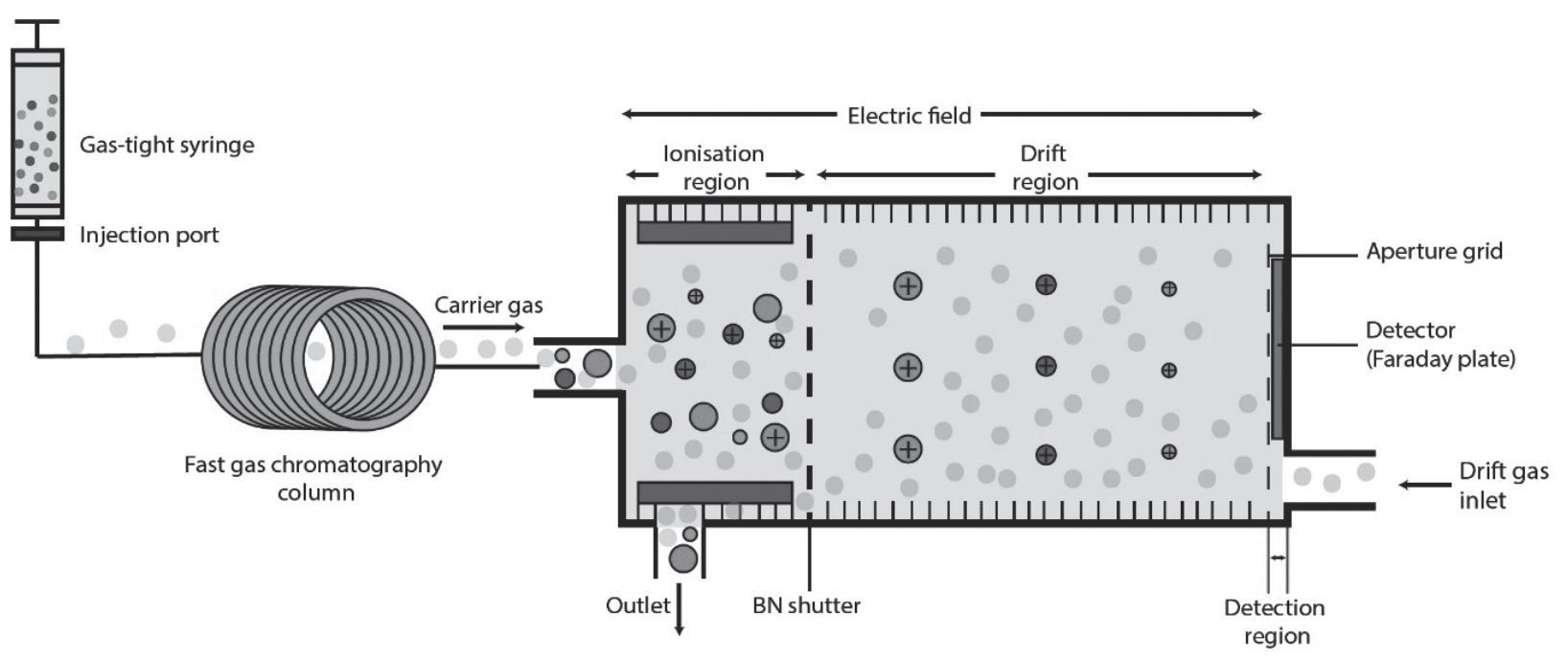

Figure 1. A diagrammatic overview of the working principles of gas chromatography-ion mobility spectrometer (GC-IMS).

of pre-processing steps were undertaken prior to chemometric analysis. The first step cropped an area of interest, reducing data points by a factor of 10. All data were aligned in the $x$-axis relative to the Reactant Ion Peak (RIP) position of the first file and thresholding to remove background was followed by $x / y$ realignment, further reducing the number of data points to below 100000 . At this stage, a 10-fold cross validation technique was applied. In each fold, around $90 \%$ of the data was used as the training set. Within the training set, features were identified using a Wilcoxon rank-sum between the two groups (Sabah vs. Peninsular Malaysia). One hundred features (data points) with the lowest $p$-values were retained and used to construct the models. This model was then applied to the remaining test set and this was repeated until each sample has a prediction as a test sample (Martinez-vernon et al., 2018). The five classification models used in this study are listed below:

- Sparse Logistic Regression;

- Random Forests;

- Gaussian Processes;

- Support Vector Machines; and

- Artificial Neural Networks.

\section{RESULTS AND DISCUSSION}

Examples of the GC-IMS spectra obtained from Sabah and Peninsular CPO samples are shown in Figure 3. GC-IMS analysis results in a threedimensional topographic plot where the $x$-axis represents IMS drift time (ms), the y-axis represents GC retention time (s) and the $\mathrm{z}$-axis represents peak height/intensity (V). Due to the three-dimensional nature of the data, each spectrum contains around 11 million data points making visual comparison of different samples arduous and inefficient. Furthermore, distinguishing less intense but perhaps important signals is not possible as they may not be readily apparent above the background noise. This is why the application of chemometrics was required in order to process data automatically, to reduce dimensionality and size, and to build classification models for discerning CPO samples by geographical origin (Sabah vs. Peninsular Malaysia).

The five different classification models (Sparse Logistic Regression, Random Forests, Gaussian Processes, Support Vector Machines, Artificial Neural Networks) include both linear and nonlinear methods. A single classification model was not selected for this study as the dataset was relatively small and until larger data sets can be tested, it is recommended that multiple classifier models should be used. In order to quantify the quality of classification results, several performance features were proposed as metrics. The estimation of such metrics is based upon the classifiers ability to distinguish classes correctly and to subsequently avoid classification failure (Martinez-vernon et al., 2018). The different quality metrics used in this article for evaluating the classification results are shown below (Pérez-Castaño et al., 2015):

- Area under curve (AUC): the area under the receiver operating characteristic (ROC) curve is a measure of the quality of classification models that can summarise the performance of a classifier into a single metric. Its value varies between 0 and 1 , although values should generally be greater than 0.5 .

- Sensitivity: also known as the true positive rate and measures the proportion of actual positives that are correctly identified as such. The range of values for this feature is 0 to 1 . 
- Specificity: also known as the true negative rate and measures the proportion of actual negatives that are correctly identified as such. The range of values for this feature is between 0 and 1.

- $p$-value: a measure to determine the significance of the results. $p 0.05$ typically indicates strong evidence against the null hypothesis meaning the result is significant.

All five models produced strong results for discerning Sabah and Peninsular Malaysia CPO samples (AUC 0.96) meaning they could correctly distinguish between samples at least $96 \%$ of the time. However, the Sparse Logistic Regression method performed best (AUC 0.98) (Table 2 and Figure 4). Since GC-IMS is a rapid, sensitive and selective, costeffective and non-destructive technique, which can be readily implemented on-site, it could be proposed as an initial screening technique for the geographical origin of $\mathrm{CPO}$, prior to the utilisation of more costly and time-consuming targeted techniques.

Whilst the aim of this study was to assess the use of GC-IMS as a fingerprinting approach for discerning samples by origin, the pipeline used in this study allowed for feature extraction to identify significant data points involved in the classification. For example, several data points may have formed a single peak that was only present in one group of samples and not the other, therefore it might have been of interest to identify this peak using the NIST2014 database and IMS library. However, in this study, there was no correlation between specific features and individual spectral peaks. The features with the greatest variance were spread across the spectra and likely represented global changes in total profiles, making peak picking and subsequent compound identification difficult. Nevertheless, this study has shown GC-IMS combined with chemometrics to be a feasible fingerprinting approach for discerning between CPO samples from Sabah and Peninsular Malaysia. Further work should be conducted on a larger sample size to increase the likelihood of detection of a specific geographical marker using feature extraction, followed by compound identification using NIST2014 and IMS databases.

Sample and group size have been major limitations in all previously published studies in this area. Our study is only one of two which has successfully discerned CPO samples by region of
Classification models:

- Sparse Logistic Regression

- Random Forest

- Gaussian Processes

- Support Vector Machines

- Neural Networks

Note: RIP - reactant ion peak.

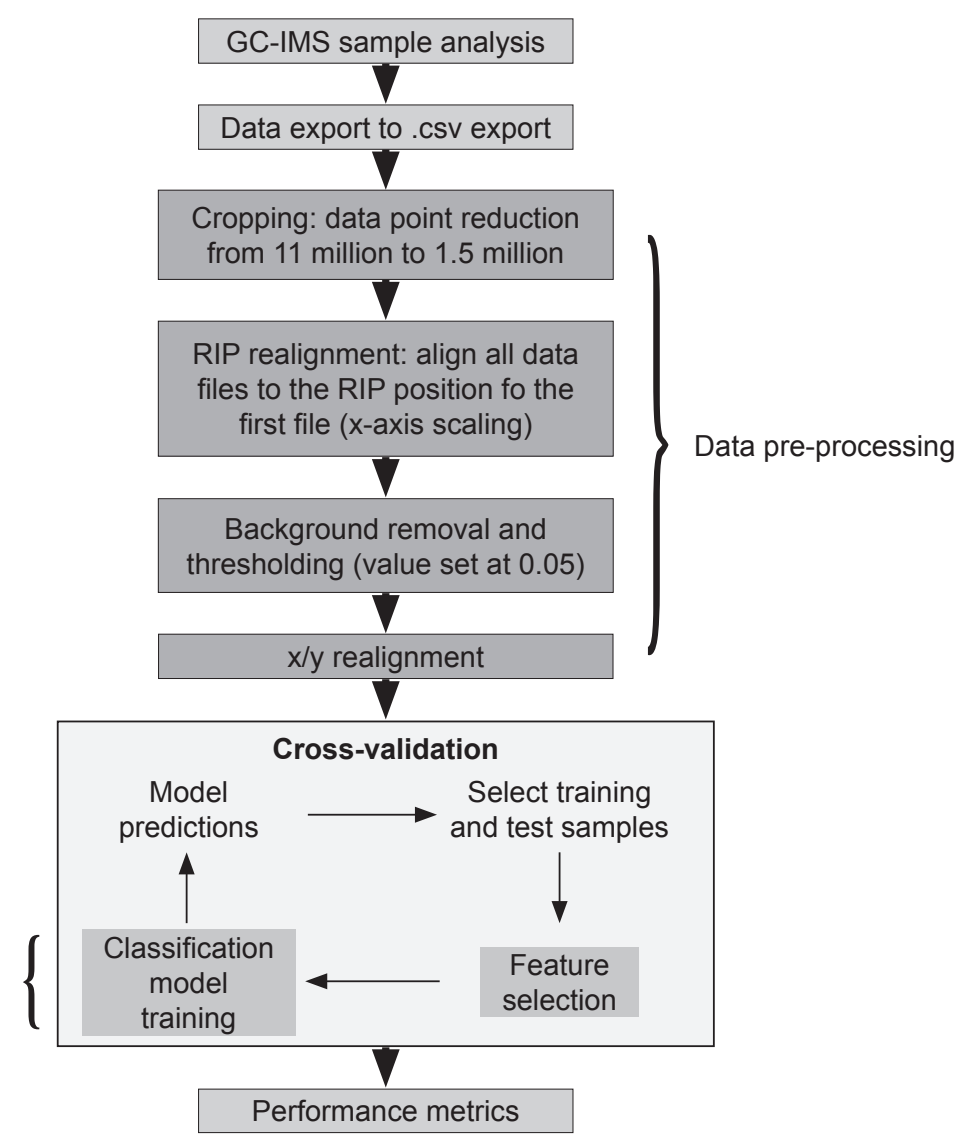

Figure 2. An overview of the general workflow used for classifying gas chromatography-ion mobility spectrometer (GC-IMS) data into Sabah or Peninsular Malaysia classes. 


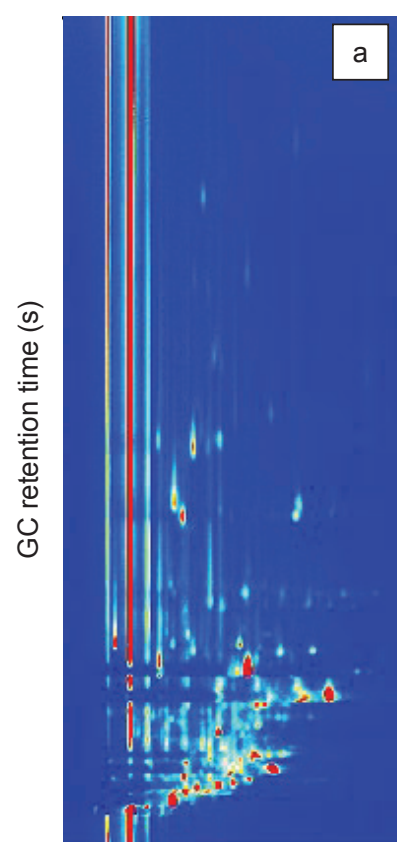

IMS drift time (ms)

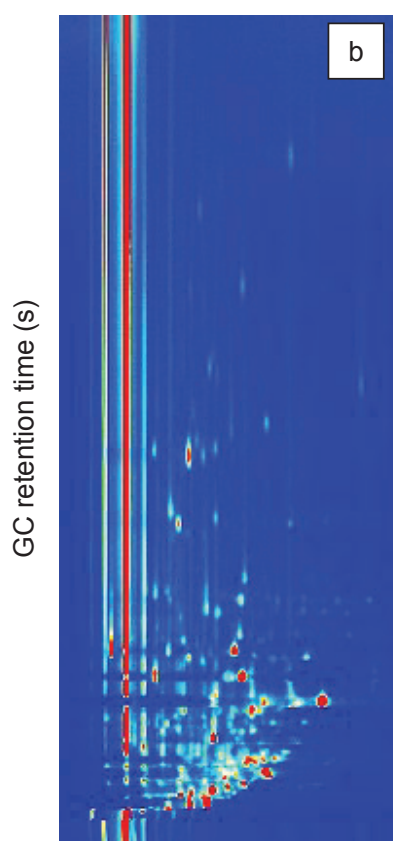

IMS drift time (ms)

Figure 3. A side-by-side comparison of typical gas chromatography-ion mobility spectrometer (GC-IMS) spectra from Sabah (a) and Peninsular Malaysia (b) crude palm oil samples.

Sparse Logistic Regression $(A \cup C=0.98)$

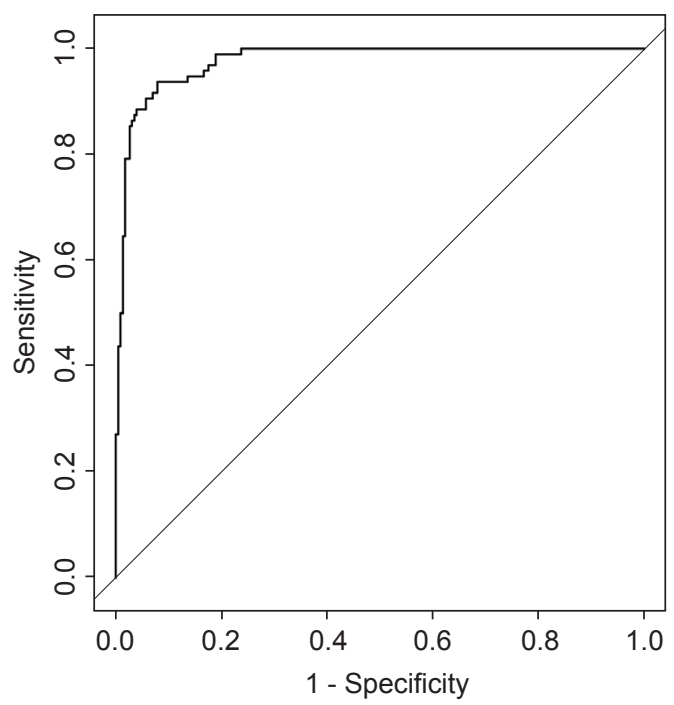

Random Forest

$(A \cup C=0.97)$

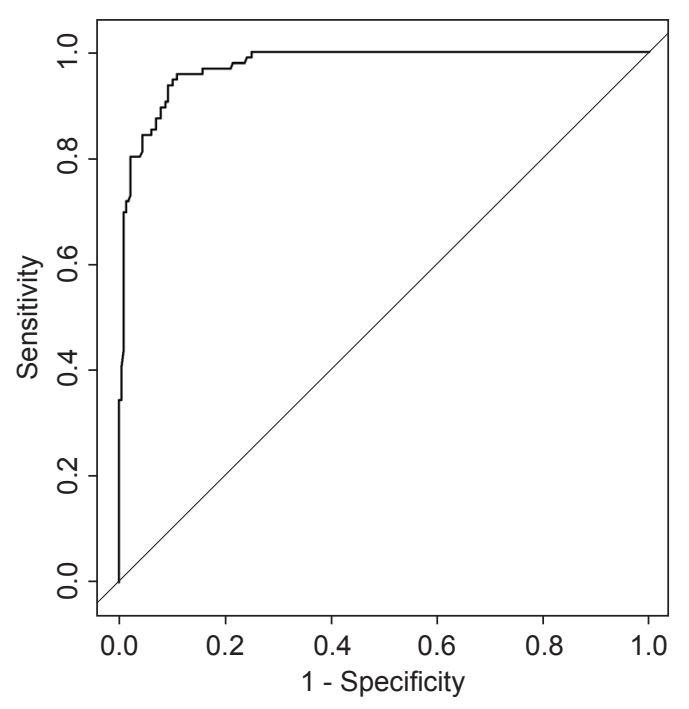

Figure 4. Examples of the receiver operating characteristics (ROC) curves, summarising the performance of each model used in study.

TABLE 2. MODEL PERFORMANCE COMPARISON FOR 100 FEATURES

\begin{tabular}{lcccc}
\hline Model & Area under curve (AUC) & Sensitivity & Specificity & $p$-value \\
\hline Sparse Logistic Regression & $0.98(95 \%$ CI: 0.96-0.99) & $0.94(95 \%$ CI: 0.87-0.98) & 0.92 (95\% CI: 0.88-0.95) & $<0.01$ \\
Random Forest & $0.97(95 \%$ CI: 0.96-0.99) & $0.96(95 \%$ CI: 0.90-0.99) & 0.84 (95\% CI: 0.84-0.93) & $<0.01$ \\
Gaussian Process & $0.96(95 \%$ CI: 0.95-0.98) & $0.91(95 \%$ CI: 0.83-0.96) & 0.91 (95\% CI: 0.87-0.95) & $<0.01$ \\
Support Vector Machine & $0.96(95 \%$ CI: 0.93-0.99) & $0.95(95 \%$ CI: 0.88-0.98) & 0.95 (95\% CI: 0.92-0.98) & $<0.01$ \\
Artificial Neural Network & $0.97(95 \%$ CI: 0.96-0.99) & $0.95(95 \%$ CI: $0.88-0.98)$ & 0.95 (CI: $0.92-0.98)$ & $<0.01$ \\
\hline
\end{tabular}


origin and is the first to do so using a fingerprinting approach combined with chemometrics, on a much larger sample set. Nevertheless, even in this work, sample set is still a limitation because recommended minimum group size for chemometric analysis to be statistically significant is 30 , which is close to that of the Peninsular Malaysia group $(n=32)$. Furthermore, due to the availability of samples, group size in this study is not optimally balanced, meaning bias may be introduced. Any further work should be conducted on larger and better balanced groups. Nonetheless, this study has demonstrated promising results using the provided sample set and has shown that increased spatial specificity can be obtained. Further work should be conducted using CPO from the same mills/regions, but further studies should also ensure that samples are collected and analysed continuously over longterm periods of several months to years in order to capture as much variation as possible. In this way, it will be possible to successfully validate such approach and train predictive models more effectively.

Analytical methods for verification of geographical provenance of palm oils will have positive implications within the industry and will support and strengthen the current administrative controls in place. Whilst VOC fingerprinting is a well-studied approach and has been successfully used for other vegetable oils, further work should be undertaken annually, using as many authentic samples as possible, to assess the impact of seasonal variation, changes in fertilisation regime, changes in processing, etc.

\section{CONCLUSION}

Fingerprinting approaches combined with use of appropriate multivariate statistics (chemometrics) is common practice for authentication of foodstuffs. However, this is the first study of its kind that has shown that the application of chemometrics to raw chromatograms of GC-IMS data, is effective for discerning CPO samples by regional geographical provenance.

A single classification model was not selected for this study as the dataset is relatively small, alternatively five different models (linear and nonlinear) were used and should continue to be used until a large enough dataset has been analysed. All models were successful in discerning CPO samples from Sabah and Peninsular Malaysia. Since GC-IMS is a rapid, sensitive and selective, cost-effective and non-destructive technique, which can be readily implemented on-site, it could be proposed as an initial screening technique for the geographical origin of $\mathrm{CPO}$, prior to the utilisation of more costly and time-consuming targeted techniques.
Such analytical methods for verifying the geographical provenance of palm oils will have positive implications within the industry and will support and strengthen the administrative controls currently in place (Goggin and Murphy, 2018). This is only one of a few which have sought to distinguish crude palm oils by geographical origin and is only the second to do so on a regional level and the only one using GC-IMS. Whilst VOC fingerprinting is a well-studied approach and has been successfully used for other vegetable oils, further work should be undertaken annually to assess the impact of seasonal variation, changes in fertilisation regime, changes in processing, etc. A larger sample set should also be studied to determine whether further spatial specificity can be obtained (i.e. at mill or plantation level).

\section{ACKNOWLEDGEMENT}

This work was partially funded by the European Social Fund through the Welsh government under a KESS2 studentship, University of South Wales and IMSPEX Diagnostics Ltd, awarded to Goggin, K A (Grant number: MAXI 20539). The authors are very grateful to Professor Saskia van Ruth at WUR for providing the CPO samples for the study.

\section{REFERENCES}

Corley, R H V and Tinker, P B H (2008). The Oil Palm. Fourth edition. Wiley-Blackwell. 592 pp.

Cumeras, R; Figueras, E; Davis, C E; Baumbach, J I and Gràcia, I (2015). Review on ion mobility spectrometry. Part 2: Hyphenated methods and effects of experimental parameters. The Analyst, 140: 1391-1410. DOI:10.1039/C4AN01101E.

Eiceman, G A; Karpas, Z and Hill, H H (2016). Ion Mobility Spectrometry. Third edition. Boca Raton: CRC Press. 444 pp.

\section{G.A.S. (2018). L.A.V v2.0.0.}

Garrido-Delgado, R; Dobao-Prieto, M D M; Arce, L and Valcárcel, M (2015). Determination of volatile compounds by GC-IMS to assign the quality of virgin olive oil. Food Chem., 187: 572-579. DOI:10.1016/j.foodchem.2015.04.082.

Garrido-Delgado, R; Mercader-Trejo, F; Sielemann, S; De Bruyn, W; Arce, L and Valcárcel, M (2011). Direct classification of olive oils by using two types of ion mobility spectrometers. Anal. Chim. Acta, 696(1-2): 108-115. DOI:10.1016/j.aca.2011.03.007. 
Goggin, K and Murphy, D J (2018). Monitoring the traceability, safety and authenticity of palm oils imported in Europe. Oilseeds and Fats, Crops and Lipids, 25(6): 1-15. DOI:10.1051/ocl/2018059.

Hauschild, A; Schneider, T; Pauling, J; Rupp, K; Jang, M; Baumbach, J I and Baumbach, J (2012). Computational Methods for Metabolomic Data Analysis of Ion Mobility Spectrometry Data - Reviewing the State of the Art. p. 733-755. DOI:10.3390/metabo 2040733.

Janin, M; Medini, S and Técher, I (2014). Methods for PDO olive oils traceability: State of art and discussion about the possible contribution of strontium isotopic tool. Eur. Food Res. Technol., 239(5): 745-754. DOI:10.1007/s00217-014-2279-8.

Koh, L P and Wilcove, D S (2008). Is oil palm agriculture really destroying tropical biodiversity? Policy Perspective, 1: 60-64. DOI:10.1111/j.1755263X.2008.00011.x.

Korifi, R; Le Dréau, Y; Molinet, J; Artaud, J and Dupuy, N (2011). Composition and authentication of virgin olive oil from French PDO regions by chemometric treatment of Raman spectra. J. Raman Spectros., 42(7): 1540-1547. DOI:10.1002/ jrs.2891.

Martinez-vernon, S; Covington, J A; Arasaradnam, R P; Id, S E; Connell, N O; Kyrou, I and Savage, R $S$ (2018). An improved machine learning pipeline for urinary volatiles disease detection: Diagnosing diabetes. PLoS ONE, 13(9): e0204425. DOI:10.1371/ journal.pone.0204425.

Meijaard, E; Garcia-Ulloa, J; Sheil, D; Wich, S A; Carlson, K M; Juffe-Bignoli, D and Brooks, T M (2018). Oil Palm and Biodiversity. A Situation Analysis by the IUCN Oil Palm Task Force. 126 pp.

Meijaard, E and Shell, D (2013). Oil-palm plantations in the context of biodiversity conservation. Encyclopedia of Biodiversity. Vol. 5. Elsevier Ltd. p. 601-612. DOI:10.1016/B978-0-12-384719-5.00340-3.

Muhammad, S A; Seow, E; Omar, A K M; Rodhi, A M; Hassan, H M; Lalung, J and Ibrahim, B (2017). Variation of $\delta 2 \mathrm{H}, \delta 18 \mathrm{O} \& \delta 13 \mathrm{C}$ in crude palm oil from different regions in Malaysia: Potential of stable isotope signatures as a key traceability parameter. Sci. Justice, 58(1): 59-66.

Obisesan, K A; Jiménez-Carvelo, A M; CuadrosRodríguez, L; Ruisanchez, I and Callao, M P (2017). HPLC-UV and HPLC-CAD chromatographic data fusion for the authentication of the geographical origin of palm oil. Talanta. p. 413-418.
Ou, G; Hu, R; Zhang, L; Li, P; Luo, X and Zhang, Z (2015). Advanced detection methods for traceability of origin and authenticity of olive oils. Anal. Methods, 7(7): 5731-5739. DOI:10.1039/c5ay00048c.

Paddison, L; Purt, J; Moulds, J; Balch, O; Riadi, Y and Ifansasti, U (2014). From rainforest to cupboard: The real story of palm oil - interactive. https:// www.theguardian.com/sustainable-business / ng-interactive/2014/nov/10 / palm-oil-rainforestcupboard-interactive, accessed on 17 January 2019.

Pérez-Castaño, E; Ruiz-Samblás, C; MedinaRodríguez, S; Quirós-Rodríguez, V; JiménezCarvelo, A M; Valverde-Som, L and CuadrosRodríguez, L (2015). Comparison of different analytical classification scenarios: Application for the geographical origin of edible palm oil by sterolic (NP) HPLC fingerprinting. Anal. Methods, 7(10): 4192-4201. DOI:10.1039/C5AY00168D.

Portarena, S; Gavrichkova, O; Lauteri, $\mathrm{M}$ and Brugnoli, E (2014). Authentication and traceability of Italian extra-virgin olive oils by means of stable isotopes techniques. Food Chem., 164: 12-16. DOI:10.1016/j.foodchem.2014.04.115.

Ruiz-Samblás, C; Arrebola-Pascual, C; Tres, A; Van Ruth, S and Cuadros-Rodríguez, L (2013). Authentication of geographical origin of palm oil by chromatographic fingerprinting of triacylglycerols and partial least square-discriminant analysis. Talanta, 116: 788-793. DOI:10.1016/j.talanta.2013.07.054.

Statista (2018). Consumption of vegetable oils worldwide from $2013 / 2014$ to $2017 / 2018$, by oil type (in million tonnes). https://www.statista. com / statistics / 263937 / vegetable-oils-globalconsumption, accessed on 12 March 2018.

Szymanska, E; Brodrick, E; Williams, M; Antony, N; Manen, H V and Buydens, L M C (2014). Data size reduction strategy for the classification of breath and air samples using multi capillary column-ion mobility spectrometry (MCC-IMS). Anal. Chem., 87: 869-875. DOI:10.1021/ac503857y.

Tres, A; Ruiz-Samblas, C; Van Der Veer, G and Van Ruth, S M (2013). Geographical provenance of palm oil by fatty acid and volatile compound fingerprinting techniques. Food Chem., 137(1-4): 142150. DOI:10.1016/j.foodchem.2012.09.094.

Tres, Alba; Van Der Veer, G; Alewijn, M; Kok, E and Van Ruth, S M (2011). Palm oil authentication: Classical and state-of-the-art techniques. Oil Palm: Cultivation, Production and Dietary Components (Penna, S A ed.). Nova Science Publishers, Inc. New York. p. 1-44. DOI:10.3213/1612-1651-10072. 